Michael Skey*

\title{
"It is their job to make sure that the long- term vision for the show ... stays intact": Using insights from the television format industry to rethink the concept of media events
}

https://doi.org/10.1515/commun-2019-0159

\begin{abstract}
The concept of media events continues to generate widespread debate among scholars around the globe. Studies that have challenged the concept's functionalist foundations have undoubtedly sharpened our thinking. Conversely, approaches that have sought to expand the concept tend to confuse rather than clarify. In this paper, we argue that events that are planned, anticipated, and involve external organizations in their design demand a specific set of analytical tools. Furthermore, we draw a further distinction between one-off events and those that are cyclical in nature, with the latter being theorized using insights from studies of the television format industry. This approach not only focuses much needed attention on the production side of media events but also on the struggles between different interest groups (rights-holders, event hosts, media producers). We illustrate our arguments by drawing upon ethnographic material from the 2014 Eurovision Song Contest.
\end{abstract}

Keywords: Media events, television formats, Eurovision Song Contest, media theory, media producers

\section{Introduction}

Dayan and Katz's concept of media events (1992) continues to provoke ongoing research and reflection from scholars interested in theorizing the significance of events and programs that interrupt media schedules and, in the process, often draw together substantial numbers of people through closely-aligned media practices (Sonnevend, 2018). The original study of Media events was quite rightly

*Corresponding author: Michael Skey, School of Social Sciences, Loughborough University, E-Mail: m.skey@lboro.ac.uk. 
criticized for its functionalist approach, and subsequent interlocutors have noted the importance of asking whether, who, and in what ways such events integrate, rather than making broad-based assumption concerning their integrative power (Couldry, 2003, pp. 61-67). More recent attempts to extend the category of media events (Hepp, 2004; Katz and Liebes, 2007; Seeck and Rantanen, 2015) have, in our view, been much less convincing and risk turning the concept into a broader dumping ground for very different phenomena, disasters, news events, political scandals, and the finals of reality TV shows.

In addressing some of these issues, this paper argues that the concept of media events should be retained to refer to events that are pre-planned, anticipated, and involve both media and non-media organizations in their development, management, and promotion. Moreover, in this paper we introduce a further distinction between one-off and cyclical media events, focusing on the latter and arguing that they may be productively theorized using broader insights from studies of the television format industry.

To illustrate our arguments, we utilize ethnographic data gathered at the 2014 Eurovision Song Contest (ESC), an annual music event that draws together audiences from around the globe. Of particular relevance will be interviews with media producers that offer a complementary perspective from 'inside the media event'. This not only demonstrates the specific features and character of cyclical events but also refocuses attention on the fascinating struggles that take place between the different interest groups - rights-holders, local media producers, sponsors, host city administrators, regional and national government agencies involved in the production-side of such events.

The paper is divided into three parts. The first provides an overview of recent discussions of the media events concept, outlining the strength and weaknesses of critiques and subsequent reformulations. Having called for greater conceptual clarity in how such events are defined, the second part offers a new framework for making sense of events that are cyclical in nature by drawing on insights from the global TV format industry. The final section provides evidence for such an approach using data from the 2014 Eurovision Song Contest as an illustrative example.

\section{Media events: A critical overview}

Recent work on media events has looked to expand the definition of the concept to incorporate a whole host of features, including disasters (Katz and Liebes, 2007, p. 416), "popular media events [tied to] ... celebrity culture” (Hepp and 
Couldry, 2010, p. 8), and "news events" (Seeck and Rantanen, 2015, p. 175). The original definition put forward by Dayan and Katz (1992) in their groundbreaking work Media events: The live broadcasting of history were far more parsimonious and referred to live events that interrupt daily routines and schedules, are preplanned and organized outside the media by large public or other bodies, involve ceremonial elements that are presented with reverence and electrify very large audiences (pp. 4-8). Crucially, they also drew on Durkheim's (1976) seminal argument around the importance of religious festivals in strengthening social ties and applied it to the modern era of mass media broadcasts. As they wrote, media events "integrate societies in a collective heartbeat and evoke a renewal of loyalty to the society and its legitimate authority" (emphasis in original, Dayan and Katz, 1992, p. 9).

This presumed integrative function of media events has been the focus of the most important critiques of the concept (see Hepp and Couldry, 2010). The problem with such a functionalist reading is that it presents an unduly simplistic view of social order and overlooks struggles for power and the cleavages (ethnic, religious, class, gender, and so on) that fragment even the most settled societies. Instead, we need to adopt a different starting point, and think not only about the ways in which such events, in orientating people's activities towards a particular time and place, may contribute to the representation of a temporarily coherent social entity (Skey, 2006), but also how such representations may be challenged by other groups (Collins, 2004; Lukes, 1975).

A second critique concerns the place of media and how we understand media power. In the original formulation, media events were viewed as "shared experiences uniting viewers with one another and with their societies" (Dayan and Katz, 1992, p. 13). This top-down approach underplays the extent to which audiences and alternative media can ignore and challenge dominant readings of such events (Kyriakidou, Skey, Uldam, and McCurdy, 2018). Such criticisms are becoming even more salient in an era of digital technologies that blur the boundaries between producers and audiences, enable a range of competing narratives around particular events, and contribute to the complexity of local, national, and regional media landscapes (Sonnevend, 2016; Ytreberg, 2017).

\section{Expanding the category: From disasters to 'popular media events'}

Another recent critique of the media events concept has been its narrow focus, with two broad arguments being made. First, Katz and Liebes (2007) have taken issue with the idea that media events should be preplanned or anticipated, 
arguing that this omits major news events that interrupt schedules and capture public attention for short periods of time. A related argument came from those who observed a move towards “eventization” (Hepp, 2004), as media producers look to interrupt regular schedules in order to capture the public's attention in a fiercely competitive marketplace. Hepp and his colleagues have argued for a new category of "popular media events" that can capture the growing importance of "consumer and celebrity cultures" (Hepp and Couldry, 2010, p. 8). In doing so, they observe that such events "break with the everyday but in a much more routine way", only monopolize media coverage in certain "cultural segments", and "do not happen 'live' but in a continuous development" (p. 8).

While it is obviously important to attend to 'events' or programs that interrupt schedules in novel ways as well as audiences' increasingly complex engagements with a variety of media, we are not necessarily persuaded that this expansion helps sharpen our understanding of these different phenomena. Indeed, we believe it is still important to draw an analytical distinction between two sets of 'events'; preplanned and unexpected, and those planned solely by media and those involving non-media organizations. In the first case, although unexpected events, such as disasters or terrorist attacks, have become a notable feature of the contemporary media landscape and regularly interrupt specialist news networks (Cushion and Lewis, 2010) and, occasionally, mainstream schedules (Liebes, 2002; Spigel, 2004), they are unplanned, usually defined by large-scale loss of life and/or damage to socio-economic systems and involve particular narratives (of heroism, victimhood, and blame) that are used to highlight institutional failings or wider social issues (Pantti, Wahl-Jorgensen, and Cottle, 2012). Put simply, it makes little sense to lump together, under an extended category of media events, the mediation of, say, a major natural disaster and the subsequent event designed to commemorate it, given the myriad differences that can be identified when they are studied in detail. Leaving aside the obvious issue of design and planning, even the representation of such events is notably different, involving access to differing types of sources, specific styles of reporting, particular levels of audience engagement as well as the varying ability of powerful institutions to shape a coherent narrative (Pantti and Wieten, 2005; Wang and Louis-Charles, 2017; Zelizer, 1992).

In a similar vein, we suggest making a further distinction between those 'events' produced by and for the media (such as the finals of reality TV shows) and those that are produced by the media but in collaboration with other institutions, such as representatives from regional and national government authorities. For instance, in the case of the ESC, a whole host of local government agencies, from logistics and security to finance and insurance, are involved in the planning and management of the event, while regional and national tourist boards often use it in place-branding campaigns (Bolin and Ståhlberg, 2015). In some instances, 
diplomatic efforts may also be tied in with such events, activities which draw in other government departments (Brownell, 2008).

This means that while 'events' produced by and for the media increasingly use many features culled from the development of 'traditional' media events (building anticipation, increased budgets to generate more of a spectacle, hyperbolic styles of reporting, cross-platform marketing) their purview tends to be much more limited and they generally operate within, rather than interrupt, 'normal' media scheduling (Hill, 2014). Moreover, as we will see, the involvement of 'external' actors, rather than just media operatives and organizations, can have a dramatic impact on the design of the event and how it is planned and managed (Skey, Kyriakidou, McCurdy and Uldam, 2016).

Part of the problem, here, may be the relative neglect of studies of the production side of media events (although see Akin, 2013; Bolin, 2009; Hepp and Kronert, 2010; Ibrus, Rohn, and Nani, 2019; McAloon, 1984; Robertson, 2018, for notable exceptions). This is despite the fact that Dayan and Katz (1992, pp. 62-73) viewed the negotiations between organizers and broadcasters as a key element in their original conceptualization. This means that questions of design and planning have been somewhat neglected, perhaps allowing for distinctions between different kinds of events and programs to blur somewhat.

It is our contention that this is analytically problematic, and instead we suggest retaining a definition of media events that refers to their pre-planned nature as well as the involvement of non-media organizations in processes of design and management. In addition to this basic definition, we also believe that an important distinction can be made between one-off events and those that are cyclical in nature, or subject to what Dayan (2010) calls "episodic re-enactments" (p. 391). In the latter case, there are particular characteristics - an overall authority that works with a local organizing body for each iteration, the shifting focus (whether that be places, performers, presenters, political systems) for each event, the balance between protecting the brand and the marketing of each event as unique, and so on - that distinguish it from one-off events.

Alongside major global sporting megaevents such as the Olympics and the FIFA World Cup, both of which take place every four years and are hosted by a different country or countries, we can also point to high-profile regional and national cyclical events. For example, an established regional event, which is becoming increasingly global in its purview, is the Eurovision Song Contest, an event hosted by a different country each year but managed by a central authority, the European Broadcasting Union. On a national level, the Dutch state organizes the annual King's Day celebrations in the Netherlands, which are hosted by a different city each year, and extensively covered by public service and other broadcasters. 
By focusing on these cyclical events, we look to support our argument that greater precision is required when trying to make sense of the various events that currently populate the media landscape. To this end, we argue that insights from the global television format industry can be used to pinpoint the key characteristics, and significance, of cyclical media events. In the next section, we outline some of the main arguments from the literature on TV formats before looking to apply these insights to the study of cyclical media events.

\section{Television formats}

Put simply, television formats are programs developed in one country that are sold to (and repurposed by) producers in other parts of the world. Popular examples would include Big Brother, Survivor, and Who Wants to be a Millionaire. In the last two decades, the popularity of television formats has risen dramatically to the extent that they now form part of a multi-billion dollar global industry and, in the process, have become some of the most watched television shows of all time (Waisbord, 2004). While there is no overriding consensus on how to define a television format, two key elements have been identified in the literature (Esser, 2010; Oren and Shahaf, 2013). First is the "distinctive narrative dimension" (Chalaby, 2011, p. 294). This refers to the specific ways in which key elements of the television program are arranged so that an identifiable "narrative progression is created" (p. 294). The format has often been discussed as a set of rules or even a recipe that producers must follow in order to develop dramatic arcs, generate particular moments of tension and conflict (commonly called "trigger moments”) (Chalaby, 2011, p. 295), and highlight the 'journey’ of key participants. The second key features are portability and adaptability, as formats are defined by the manner in which they cross borders and appeal to audiences in multiple locations (Esser, 2010). At the heart of this process lies what is called the production bible, which sets out key aspects of the show's design, budget, marketing, organization, and so on. For while some degree of local adaptation is permitted, the 'bible' is designed to ensure the program remains faithful to the original and, in theory, has the best chance of success in new markets. In order to protect their brand and ensure its continuing profitability in international markets, the format's copyright holders may also send out consultant producers to provide advice to local teams (Chalaby, 2011, p. 296).

When thinking about the relevance of these insights to media events, it's worth noting that Daniel Dayan (2008, p. 391) observed in passing the similarities between the script demanded of host countries by the International Olympic Committee (IOC) of host countries and the work done by the Dutch television 
company Endemol in ensuring that their reality television shows were franchised into successful reproductions. Yet to our knowledge this insight has never been fully developed as attempts to expand the category of media events have tended to dominate the literature in recent times. Alternatively, it is our contention that this idea may prove particularly useful in distinguishing between different types of media events, thereby sharpening our understanding of the contemporary media landscape.

In the next section, we focus on the design, production and significance of a particular type of media event that is cyclical in nature and therefore can be analytically distinguished from other one-off, pre-planned events.

\section{Defining cyclical media events}

One of the main features of cyclical media events is the key role played by a central organizing authority that looks to ensure consistency across time when it comes to many aspects of their design, organization, and promotion. For instance, the Olympic Games feature a range of clearly defined elements, the Olympic Torch relay, the Opening and Closing Ceremonies, the lighting of the Olympic flame, a fixed schedule for the 'blue riband' competitions, medal ceremonies with anthems and flags that cannot be tampered with, no matter the host city. To this end, the International Olympic Committee has a 276-page 'production bible', entitled the Host City Contract, which "is designed to ensure that all parties understand and agree to a specific set of responsibilities that guarantee successful Olympic Games and create a beneficial legacy for the Host City and the Olympic Movement" (IOC, 2016, p. 13). This contract covers a panoply of issues, ranging from signage (sponsorship and branding is, of course, a major concern) to sustainability and ticketing. Moreover, while host cities and nations are obviously encouraged to emphasize their own unique attributes and cultural traditions, there are often quite ferocious struggles between the IOC and local organizing committees when it comes to, for instance, what is featured in the various ceremonies (Tomlinson, 1996), how an 'Olympic legacy' is developed and evaluated (Cashman and Horne, 2013), the media coverage of the various sporting competitions (Marshall, Walker, and Russo, 2010), and so on. Similar patterns can be seen in relation to the organization and promotion of the football world cup, where the main organizing body, FIFA, uses its considerable power to primarily ensure: consistency in the way in which the competition is marketed, the pre-eminence of the various FIFA sponsors, and the global image of the game of football, sometimes at the expense of the hosts and football fans (Eisenhauer, 2013, p. 260). FIFA also produces guidelines for host cities (its production bible) which not only outline the 
rules of the competition but how it is to be organized and, of course, marketed (FIFA, 2017). There is some leeway for each host country when it comes to issues such as designing the official mascot and 'look' of the tournament (FIFA, 2017), but as for television formats, while "local producers can be allowed to alter the 'flesh' of a format [they] ... can never touch the 'skeleton'”(Chalaby, 2011, p. 295).

The cyclical nature of these type of events, whether they are held on an annual, bi-annual or quadrennial basis, not only means that they become a regular fixture of media calendars and schedules, anticipated by media organizations and audiences alike, but also that an individual event is organized, represented, and understood as part of an ongoing series of such events.

Now, of course, one-off events are also never framed in isolation. A contemporary royal wedding, for instance, will be discussed in relation to historical precedents. However, these are relatively rare phenomena and are not anticipated in the same way as a cyclical media event. They are, therefore, subject to different cycles of production and representation. In the words of Daniel Dayan (2010), such events are akin to "repertory theater, each enactment means to be different. Yet the play or event must be recognizable from repeat to repeat, from episode to episode" (p. 392).

If we take the last five Olympic Games as an example, it is possible to see how each individual event followed the same format and, at the same time, made reference to, and looked to distinguish itself in relation to, the preceding one. Sydney in 2000 sought to emphasize national idiosyncrasy, partly in response to critiques of the previous event, held in Atlanta, US, which argued that the games had become too commercialized (Heinz-Housel, 2007). In 2004, Athens, beset by concerns over its infrastructure and organization, made specific reference to history and the idea that the games were returning "home" (Traganou, 2010). Beijing in 2008 was an overtly expensive spectacle designed to emphasize China's growing power and influence (Brownwell, 2008), while, in contrast, London 2012 framed its "austerity" games in terms of legacy and cultural diversity (Silk, 2011). The most recent iteration, in Rio, looked to side-step organizational issues and high-profile political protests by foregrounding the novelty of the South American location and issues around progress and development in the Global South (Millington and Darnell, 2014). In some cases, as in the Moscow 1980 and Los Angeles 1984 Olympics, these references to previous events are made explicit (Sarantakes, 2009), but in most instances they are more subtle inflections.

Likewise, it is important to note that individual event organizers not only position themselves against other iterations but also borrow and learn from them. A recent critical study of the South African and Brazilian football World Cups has noted how the organizers of the latter drew on arguments from the former around development and economic prosperity in the Global South, in order to try and convince skeptical civil society groups inside the country as well as external 
sponsors and media organizations (Schausteck de Almeida, Bolsmann, Marchi Junior, and de Souza, 2015).

The second part of this paper will develop some of these arguments in relation to the Eurovision Song Contest, drawing on a range of empirical examples from inside the media event. In the next section, we provide details of how these data were generated and analyzed and then a brief historical overview of the Eurovision Song Contest (ESC).

\section{Data collection and analysis}

This paper draws upon ethnographic research conducted during and after the 2014 ESC, which took place in Copenhagen from May 6 to 10. We spent the week leading up to the final in Copenhagen attending the formal performances that took place on one of the city's small islands, labelled 'Eurovision Island'. These included two semi-finals, two dress rehearsals, and two finals (one for the jury and one for the television broadcast). However, the televised media event of the ESC final is the culmination of a week of Eurovision-related events and festivities in the host city, where fans, journalists, and sponsors can participate in a range of Eurovision-themed activities. Moving through these sites, we talked to more than 80 fans both in individual and, more often, group interviews. We also spoke to several people working in the main arena, in the Eurovision Village and Café and, with access to the media center, to journalists covering the event for both mainstream and specialist outlets. After the event itself, we secured interviews with senior Danish television producers employed by the Danish Broadcasting Corporation (DR). These individuals are experienced producers of major television events and worked closely with the EBU on planning and organizing the ESC in Copenhagen that year. All interview data and field-notes were inputted into NVivo, and then initial coding took place. Key themes were identified, including fandom, media uses, media representations, organization and planning, politics, and identities. For the purposes of this paper, we are drawing primarily on data related to the themes of organization and planning and politics and using extracts from the interviews with the main event producers.

\section{The Eurovision Song Contest: A brief overview}

Ostensibly a competition to decide the best original pop song among member states of the European Broadcasting Union (EBU), the ESC has become the most 
popular international music event in the world, attracting annual audiences of over 150 million (Eurovision Song Contest, 2014). As well as the live broadcast, the ESC also generates debates across other media. For instance, Twitter reported 5,384,678 tweets sent around the 2014 final (which compares with around 11 million for that year's Oscars ceremony) (Twitter 2014).

In terms of its history, claims are often made (Bourdon, 2007, p. 264) that the ESC was part of a socio-cultural project designed to unify Europe after the travails of the Second World War, but the historical record largely shows this to be wishful thinking (Henrich-Franke, 2012). Rather, the focus of the fledgling EBU (created in 1950) was in developing common technological and judicial frameworks for the new medium of television (Henrich-Franke, 2012, p. 35). In the contemporary era, the contest remains a notable feature of the European media landscape and continues to engage viewers, hosts, performers and sponsors. For instance, it interrupts normal public service broadcasting schedules across the member states for one evening in May and continues to generate substantial media coverage and capture public attention in the lead-up to, and during, the broadcasting of the event (Skey, Kyriakidou, McCurdy and Uldam, 2016). In short, its traditional slot and cyclical nature mean that it contributes to the familiar patterning of media schedules for audiences across Europe and, increasingly, beyond.

In the following sections, we use some of our empirical materials to highlight the specific features of interruptive events such as the ESC, applying earlier insights from our discussions of the television format industry to lend weight to the argument that they can be viewed as a specific type of 'cyclical' media event.

\section{The EBU and the ESC production bible}

As the long-term custodian of the ESC, the EBU is "directly responsible for overseeing and guiding all aspects of the finances, organization, creative planning and execution" (European Broadcasting Union, 2015, p. 10). Each year it works closely with the member that won the previous year's competition to identify a suitable venue, market the event, design a program, and ensure that the broadcast and other facilities are in order. Here, a production bible, which covers everything from the permitted content of songs and the eligibility of performers to the workings of the voting system, is again used to ensure that there is consistency over time, and the competition retains a unique 'brand' within an increasingly competitive (and global) media landscape (more of which below). It is also designed to reduce the potential for disruptive elements that might damage the standing of the competition or cause problems for future hosts. The EBU has to deal with a range of governments and media organizations both in Europe and 
beyond, and such a high-profile event represents an ideal opportunity for many such groups to try and promote their interests. Therefore, the EBU is particularly concerned about trying to portray the ESC as an apolitical event and ensuring that overt political statements are omitted. To this end, the rules of the competition specifically state that:

The ESC is a non-political event ... No message promoting any organization, institution, political cause or other cause, company, brand, product or service should be allowed in the Shows and within any official ESC premises (i.e., at the venue, during the Opening Ceremony, the Eurovision village, the Press Centre etc.). A breach of this rule may result in disqualification. (EBU, 2018)

Moreover, these are not idle threats. Turkey was suspended for two years when the state broadcaster refused to transmit coverage of the Greek entry in 1976 (Akin, 2013). More recently, Georgia's 2009 entry, a thinly disguised attack on the Russian leader Vladimir Putin, was banned from the competition, and in 2019, the Icelandic entry was fined for a pro-Palestinian protest in the final, which was hosted by Israel.

The voting system is another element that is carefully managed by the EBU, with recent shifts to the current mixed system in an attempt to manage concerns over voting irregularities, improve audience engagement, and ensure a wider range of winners after the dominance of newer entrants in the $2000 \mathrm{~s}$ (Fricker and Gluhovic, 2013, pp. 3-4).

\section{Keeping the format intact}

While the EBU is able to control many aspects of the ESC, from monitoring the activities of national broadcasters through the use of undercover agents (Akin, 2013) to placing restrictions on the size of flags that fans are able to bring in to the venue, we should also be aware that different groups will want quite different things from the event and will attempt, where possible, to influence its design accordingly. For the hosts, the chance to promote the city, region, and/or nation to a global audience is generally seen to offset the cost and effort of producing the event. The host broadcaster is given opportunities within the program itself to market the country, and will often use other techniques, the involvement of government officials or local celebrities, awe-inspiring facilities or production technologies, to further advertise its economic, political, and cultural attributes to those watching (Bolin, 2006).

However, it is also worth noting that the EBU continues to place limits on these activities in order to both discourage an ongoing 'arms race' in relation to 
expenditure and ensure that the 'format stays intact'. As we were told by the two producers from the Danish broadcasters, DR:

It is their [the EBU's] job to make sure that the long-term vision for the show or the format stays intact. And each broadcaster has an incentive to try and make this year the best and wildest one yet, we want to break previous frames and patterns and we want to do something different and crazy. And they sit there and say yes, sure, but next year it will take place somewhere different and they will also want to do something crazy. And they therefore discourage the wildness and craziness ... So some kind of continuity has to be kept and they are in charge of that on a daily basis. The reference group comes in on a continuous structural checkup with a fixed cadence and then if there are some issues that you cannot agree on, then they intervene.

This extended extract highlights several key issues. First, it shows the extent to which cyclical media events, such as the ESC, are viewed as a format by the Danish producers of the show. Earlier we discussed how copyright holders of TV formats were primarily concerned with protecting their brand on a global stage to ensure its future profitability and, in the process, used consultant producers to provide advice to local teams. This is exactly what we see happening in the case of the ESC, where an established reference group works with local organizers to ensure that the basic framework is adhered to. Second, is the key issue of consistency across time. The literature on the topic often only focuses on key features or controversies tied to individual events (Akin, 2013; Štětka, 2009), thereby failing to take into account the ways in which many of the most prominent are cyclical in nature, not only pre-planned as individual events, but also within a wider framework that is the direct purview of the main organizing body and/or rights holder. The IOC, FIFA, and the EBU have a longer-term perspective that in most cases will trump the shorter-term objectives of local hosts. Likewise, focusing on the production side not only highlights the tensions between different stakeholders but, above all, points to the very different nature of such a pre-planned, interruptive event.

\section{The brand will continue to live on}

The second extract we want to point to in this paper also deals with developments over time but, in this case, looks at how events such as the ESC are refined as a result of the contributions and innovations of different local organizers. We noted earlier that formats are often strengthened when they move into different markets as producers can evaluate particular features so as to better see which work and do not work. The following extract, again taken from our interview with 
the Danish television producers, highlights this very process in relation to a cyclical media event.

\begin{abstract}
There is the core structure and core format - which looks the way it does - and then there are those ten per cent that you might move a bit. And they ought to, if this Eurovision concept is to survive for many years to come, then it ought to year after year in certain areas be an innovative process. So ... you ... build on each other's work year after year by bringing along what worked the previous years. The Austrians have taken our postcard ideas - the postcards were previously this thing where you stand on a beach in Greece and wave - but we tried to get closer to the artists, to see them in their normal clothes and see them do something, etc. They are taking our idea and developing it further. So we have to accept that they do a better job than us. But it is things like this that ensures that the brand will continue to live on.
\end{abstract}

As TV formats travel, they start to contain a certain amount of local knowledge. Ideas that are tried out successfully in a market become part of the production bible, while subsequent licensees are warned against previous failures. According to Sue Green, an established producer, "a format is a show that has 'been debugged' to remove 'the mistakes that have been made that won't be made again'” (Green quoted in Chalaby, 2011, p. 295). When it comes to the production of large-scale, pre-planned media events, tensions between different groups are a noticeable feature although those involved are generally interested in producing a spectacular and successful show. They are, therefore, also open to building on the achievements of previous iterations and incorporating noteworthy features that can help their own event run more smoothly or attract attention in what has become a fiercely competitive media environment. This delicate balance between protecting the format and making each show a unique performance is what marks out major media events that are cyclical in nature. It is also something that distinguishes them from one-off media events and other events that interrupt media schedules. This idea of format-building as a continuous process can also be seen, from a slightly different perspective, in our final example, which points to the ways in which the EBU responded to a controversial incident in 2014 and then subsequently adapted their procedures the following year.

\title{
Another 'bug' in the system?
}

As we noted above, the EBU makes a concerted effort to ensure that the ESC remains 'apolitical'. This is an almost impossible task, and one of the other major stories of the 2014 competition was the fact that a clearly audible group of fans in the arena booed the Russian entry, 17-year old twins the Tolmachevy Sisters. As 
those we spoke to at the competition confirmed, this was largely a protest against legislation that criminalized the promotion of LGBT lifestyles in Russia (Skey, Kyriakidou, McCurdy and Uldam, 2016). This was an unprecedented response to a performance at the ESC and posed a specific challenge for both the EBU and the Danish broadcasters.

In the first instance, organizers at the 2014 ESC final tried to persuade dissenting fans with announcements from the floor manager and the presenters of the show. When these exhortations failed, the organizers then resorted to their control over the broadcast technology to try and manage the impact of these activities. As the two senior representatives from the Danish public service broadcaster told us when questioned about the EBU response to the booing:

They (the EBU) asked if we could lower the volume level? And here we caved a bit on the live show itself and turned it down a bit. Turned the volume down a bit. But it demanded - in reality it was mostly about trying to balance the competition in such a way that the Russian girls received neither sympathy nor hatred, so really it was about trying to level the playing field. So we tried to do that - it was a huge dilemma.

As well as highlighting the struggles that take place between organizers and media producers during a pre-planned event, thus re-emphasizing the importance of studying every aspect of their design and management, this incident also led the EBU to try and 'debug' the following year's event through the introduction of what was labelled as 'anti-booing technology'! According to an article in the Moscow Times, which quoted Jarmo Siim, the Communications Coordinator for Eurovision, "It was very embarrassing for us last year when this happened, as it is not in the spirit of the contest ... We are here to build bridges, as the motto [of the 2015 competition] says" (Foroudi, 2015). Siim also noted that "sound reducers had been installed in case of any booing but 'Plan A is to use regular audience sound'. These were apparently one of several options to reduce any 'unfriendly sounds' from the crowd ..." (Foroudi, 2015).

The response to this incident once again illustrates the extent to which cyclical media events involve very particular styles of organization and management based on the fact that they are a regular feature of the socio-political and media landscape. In the case of the ESC, the EBU has the advantage of being able to rely on an established format to try and ensure that such disruptions are kept to a minimum but must also adapt quickly to any challenges that do emerge at any one event so that they do not happen again. At the same time, established structures need to be reinvigorated to ensure that the event maintains its visibility, popularity, and status, and there is always a balance to be struck between the needs of the organizers and the objectives of the hosts and media producers. The ongoing nature of such events and these tensions are significant in marking them 
out from one-off events and again point to the importance of sharpening our analytical tools and refining conceptual categories when it comes to making sense of what is an increasingly complex media environment.

\section{Conclusion}

Recent work on media events has been significant in calling into question the concept's functionalist origins and noting the growing complexity of global media landscapes. Notwithstanding, these important critiques, the expansion of the concept to take in a growing range of interruptive events (disasters, news, reality TV shows, and so on) is problematic, confusing issues where clarity and precision is required to make sense of these shifts. Therefore, we have first drawn a distinction between one-off and cyclical media events and used insight from the global TV format industry to focus on the particular features of the latter that mark them out in terms of their organization, production, and promotion. As cyclical media events are organized on a regular basis, they become a feature of media schedules and, in the process, are anticipated by media industries and audiences. They are managed by a governing organization that works in combination with local media producers and authorities. As for television formats, they are defined by the use of a production bible, negotiations between rights-holders and local producers, and the need to maintain a consistent brand over time whilst allowing for local adaptations. Furthermore, as such events are generally viewed as part of an ongoing series, they are generally defined and represented in relation to previous and subsequent iterations. Adopting such a position allows us to sharpen our thinking about the range of interruptive events that pattern, and increasingly complicate, media schedules and narratives around the globe as well as focusing attention on the particular impact and significance of events that are pre-planned and organized by a range of media and non-media actors.

\section{References}

Akin, A. (2013). Turkey, the Middle East \& the Media: "The reality is not as it seems from Turkey": Imaginations about the Eurovision Song Contest from its production fields. International Journal of Communication, 7, 19. Retrieved August 22, 2019 from http://ijoc. org/index.php/ijoc/article/view/1899.

Bolin, G. (2006). Visions of Europe. Cultural technologies of nation-states. International Journal of Cultural Studies, 9(2), 189-206 
Bolin, G. (2010). Media events, Eurovision and societal centers. In N. Couldry, A. Hepp, \& F. Krotz (Eds.). Media events in a global age. London: Routledge.

Bolin, G., \& Ståhlberg, P. (2015). Mediating the nation-state: Agency and the media in nationbranding campaigns. International Journal of Communication, 9, 19.

Bourdon, J. (2007). Unhappy engineers of the European Soul. The EBU and the woes of pan-European Television. International Communication Gazette, 69(3), 263-280.

Brownell, S. (2008). Beijing's games: What the Olympics mean to China. Lanham, MD: Rowman \& Littlefield.

Cashman, R., \& Horne, J. (2013). Managing legacy. In S. Frawley \& D. Adair (Eds.). Managing the Olympics. London: Palgrave Macmillan.

Chalaby, J. K. (2011). The making of an entertainment revolution: How the TV format trade became a global industry. European Journal of Communication, 26(4), 293-309.

Collins, R. (2004) Rituals of solidarity and security in the wake of terrorist attack. Sociological Theory, 22, (1), 53-87.

Couldry, N. (2003). Media rituals: A critical approach. London: Routledge.

Cushion, S., \& Lewis, J. (Eds.) (2010). The rise of 24-hour news television: Global perspectives. New York: Peter Lang.

Dayan, D. (2010). Beyond media events, disenchantment, derailment, disruption. In N. Couldry, A. Hepp, \& F. Krotz (Eds.). Media events in a global age. London: Routledge.

Dayan, D., \& Katz, E. (1992). Media events. Cambridge, MA: Harvard University Press.

Durkheim, E. (1976). The elementary forms of the religious life. Routledge: London.

Eisenhauer, S. (2013). Managing event places and viewer spaces: Security, surveillance and stakeholder interests at the 2010 FIFA World Cup in South Africa (unpublished PhD thesis). Sydney, Australia: University of Technology Sydney.

Esser, A. (2010). Television formats: Primetime staple, global market. Popular Communication, 8(4), 273-292.

European Broadcasting Union (2015). Eurovision Song Contest 2015: Media handbook. Retrieved January 18, 2018 from https://www.eurovision.tv/upload/press-downloads/2015/ MediaHandbook_ESC2015.pdf.

Eurovision Broadcasting Union (2018). Rules of the $63^{\text {rd }}$ ESC. Retrieved January 18, 2018 from https://eurovision.tv/about/rules.

Eurovision Song Contest (2014, June). “Eurovision Song Contest 2014 reaches 195 million worldwide”. Retrieved September 14, 2019 from http://www.eurovision.tv/page/ news?id=eurovision_song_contest_2014_reaches_195_million_worldwide.

FIFA (2017). Guidelines for the use of FIFA's official marks. Retrieved January 18, 2018 from http://resources.fifa.com/mm/document/affederation/marketing/02/85/05/06/2018fifa worldcuppublicguidelines_en_aug2017_neutral.pdf.

Foroudi, L. (2015). Anti-booing technology set up for Russia at Eurovision. Moscow Times, 19 May. Retrieved September 14, 2019 from http://www.themoscowtimes.com/arts_n_ideas/ article/anti-booing-technology-set-up-for-russia-at-eurovision/521779.html.

Fricker, K., \& Gluhovic, M. (Eds.) (2013). Performing the 'New' Europe: Identities, feelings and politics in the Eurovision Song Contest. London: Palgrave Macmillan.

Georgiou, M. (2008). "In the end, Germany will always resort to hot pants": Watching Europe singing, constructing the stereotype. Popular Communication, 6(3), 141-154.

Heinz-Housel, T. (2007). Australian nationalism and globalization: Narratives of the nation in the 2000 Sydney Olympics opening ceremony. Critical Studies in Media Communication, 24(5), 446-461. 
Henrich-Franke, C. (2012). Creating transnationality through an international organization? The European Broadcasting Union's (EBU) television programme activities. In A. Fickers, \& C. Johnson (Eds.), Transnational television history: A comparative approach. London: Routledge.

Hepp, A. (2004). Radio and popular culture in Germany. Radio culture between comedy and eventization. In A. Crisell (Ed.), More than a music box. Radio in a multi-media world pp. 189-212). New York: Berghahn Press.

Hepp, A. \& Couldry, N. (2010). Introduction. In N. Couldry, A. Hepp, \& F. Krotz (Eds.), Media events in a global age. London: Routledge.

Hepp, A. \& Krönert, V. (2010). Religious media events: The Catholic “World Youth Day" as an example of the mediatization and individualization of religion. In N. Couldry, A. Hepp, \& F. Krotz (Eds.), Media events in a global age. London: Routledge, 265-282.

Hill, A. (2014). Reality TV. London: Routledge.

Ibrus, I., Rohn, U., \& Nanì, A. (2019). Searching for public value in innovation coordination: How the Eurovision Song Contest was used to innovate the public service media model in Estonia. International Journal of Cultural Studies, 22(3), 367-382.

IOC (2016). Host city contract: Operational requirements. Retrieved January 18, 2018 from https://stillmed.olympic.org/media/Document\%20Library/OlympicOrg/Documents/ Host-City-Elections/XXXIII-Olympiad-2024/Host-City-Contract-2024-OperationalRequirements.pdf.

Katz, E., \& Liebes, T. (2007). “No more peace!”: How disaster, terror and war have upstaged media events. International Journal of Communication, 1. Retrieved October 20, 2019 from http://ijoc.org/index.php/ijoc/article/view/44.

Kyriakidou, M., Skey, M., Uldam, J., \& McCurdy, P. (2018). Media events and cosmopolitan fandom:'Playful nationalism'in the Eurovision Song Contest. International Journal of Cultural Studies, 21(6), 603-618.

Liebes, T. (2002). Television's disaster marathons: A danger for democratic processes? In J. Curran, \& T. Liebes (Eds.), Media, ritual and identity. London: Routledge.

Lukes, S. (1975). Political ritual and social integration. Sociology, 9(2), 289-308.

MacAloon, J. (1984). Olympic Games and the Theory of Spectacle. In J. MacAloon (Ed.), Modern societies. Rite, Drama, Festival, spectacle: Rehearsals toward a theory of cultural performance. Philadelphia: ISHI.

Marshall, P. D., Walker, B., \& Russo, N. (2010). Mediating the Olympics. Convergence, 16(3), 263-278.

Millington, R., \& Darnell, S. C. (2014). Constructing and contesting the Olympics online: The internet, Rio 2016 and the politics of Brazilian development. International Review for the Sociology of Sport, 49(2), 190-210.

Oren, T., \& Shahaf, S. (Eds.) (2013). Global television formats: Understanding television across borders. Routledge: London.

Pantti, M., Wahl-Jorgensen, K., \& Cottle, S. (2012). Disasters and the media. New York: Peter Lang.

Pantti, M., \& Wieten, J. (2005). Mourning becomes the nation: Television coverage of the murder of Pim Fortuyn. Journalism Studies, 6(3), 301-313.

Robertson, C. (2018). The media event build-up phase: A site of contestation and counternarratives. International Journal of Communication, 12, 20.

Sarantakes, N. (2009). Moscow versus Los Angeles: The Nixon White House wages Cold War in the Olympic selection process. The Olympics and the Cold War. Cold War History, 9(1), 135-157. 
Schausteck de Almeida, B., Bolsmann, C., Marchi Junior, W., \& de Souza, J. (2015). Rationales, rhetoric and realities: FIFA's World Cup in South Africa 2010 and Brazil 2014. International Review for the Sociology of Sport, 50(3), 265-282.

Seeck, H., \& Rantanen, T. (2015). Media events, spectacles and risky globalisation: A critical review and possible avenues for future research. Media, Culture \& Society, 37(2), 163-179.

Skey, M. (2006). 'Carnivals of Surplus Emotion?' Towards an Understanding of the Significance of Ecstatic Nationalism in a Globalising World. Studies in Ethnicity and Nationalism, 6(2), 143-161.

Skey, M., Kyriakidou, M., McCurdy, P., \& Uldam, J. (2016). Staging and engaging with media events: A study of the 2014 Eurovision Song Contest. International Journal of Communication, 10, 3381-3399.

Silk, M. (2011). Towards a sociological analysis of London 2012. Sociology, 45(5), 733-748.

Sonnevend, J. (2016). Stories without borders: The Berlin Wall and the making of a global iconic event. Oxford: Oxford University Press.

Sonnevend, J. (2018). Media events today. Media, Culture \& Society, 40(1), 110-113.

Spigel, L. (2004). Entertainment wars: Television culture after 9/11. American Quarterly, 56(2), 235-270.

Štětka, V. (2009). Media events and European visions: Czech Republic in the 2007 Eurovision Song Contest. Communications, 34(1), 21-38.

Tomlinson, A. (1996). Olympic spectacle: Opening ceremonies and some paradoxes of globalization. Media, Culture \& Society, 18(4), 583-602.

Traganou, J. (2010). National narratives in the opening and closing ceremonies of the Athens 2004 Olympic Games. Journal of Sport and Social Issues, 34(2), 236-251.

Twitter (2014, May 11). “Five million Tweets for \#Eurovision 2014”. Retrieved September 24, 2019 from https://blog.twitter.com/en-gb/2014/five-million-tweets-for-eurovision-2014.

Waisbord, S. (2004). McTV: Understanding the global popularity of television formats. Television \& New Media, 5(4), 359-383.

Wang, Y., \& Louis-Charles, H. M. (2017). Empirical examination of the theory of disaster marathon: A case study of the local television coverage following the 2014 Ludian, China earthquake. The Communication Review, 20(4), 246-276.

Ytreberg, E. (2017). Towards a historical understanding of the media event. Media, Culture \& Society, 39(3), 309-324.

Zelizer, B. (1992). Covering the body: The Kennedy assassination, the media, and the shaping of collective memory. Chicago, IL: University of Chicago Press. 